\title{
LEITURA COMPARADA INTERAMERICANA DA LITERATURA AMERÍNDIA
}

\section{AN INTERAMERICAN COMPARATIVE INTERPRETATION OF AMERINIDIAN LITERATURE}

Zilá Bernd ${ }^{1}$

\begin{abstract}
Resumo: Em seu último livro, Rita Olivieri-Godet desvela as vozes de mulheres ameríndias nas literaturas brasileira e quebequense, elaborando uma reflexão aprofundada e sensível sobre a obra de duas escritoras indígenas do Brasil e duas do Quebec.
\end{abstract}

Palavras-chave: Rita Olivieri-Godet; Eliane Potiguara; Graça Graúna; Naomi Fontaine; Natasha Kanapé Fontaine

\begin{abstract}
In her last book, Rita Olivieri-Godet unveils the voices of Amerindian women in Brazilian and Quebec literature, elaborating an in-depth and sensitive reflection on the work of two female indigenous writers from Brazil and two from Quebec.
\end{abstract}

Keywords: Rita Olivieri-Godet; Eliane Potiguara; Graça Graúna; Naomi Fontaine; Natasha Kanapé Fontaine

OLIVIERI - GODET, Rita. Vozes de mulheres ameríndias nas literaturas brasileira $e$ quebequense. Rio de Janeiro: Makunaima, 2020. (http://edicoesmakunaima.com.br/catalogo/2critica-literaria/38-vozes-de-mulheres-amerindias-nas-literaturas-brasileira-e-quebequense)

A temática abordada neste recente livro da professora Rita Olivieri-Godet, da Universidade de Rennes 2 e pesquisadora do Institut National de France, é das mais relevantes já que ainda vivemos no Brasil e nas Américas em geral, tempos de apagamento, de silenciamento de obras e autores que não trafegam no main-stream literário. Assim, só recentemente a literatura negra ou afro-brasileira vem sendo estudada, revelando-se sua presença efetiva nas letras brasileiras. A literatura indígena, ou como Rita Olivieri-Godet prefere chamar, ameríndia, talvez tenha merecido ainda menos atenção permanecendo ausente até bem recentemente. Salientem-se os estudos de Eloína Prati dos Santos (UFRGS) e de Rubelise da Cunha (FURG) que envidaram esforços nesse sentido, publicando estudos sobre Eliane Potiguara e sobre autores autóctones de língua inglesa do Canadá.

Rita Olivieri-Godet que, de sua cátedra de literatura brasileira em Rennes II, vem tornando visível a literatura brasileira para o leitorado francês, interessa-se há bastante tempo pelas literaturas ameríndias, tentando com suas pesquisas desfazer a invisibilidade que as cerca. Em 2013, publicou A alteridade ameríndia na ficção contemporânea das Américas (Brasil, Argentina, Quebec), pela editora Fino Traço, de Belo Horizonte. Nessa obra, a autora procurou retraçar as representações ou figurações da alteridade ameríndia nas literaturas brasileira,

\footnotetext{
${ }^{1}$ Professora da Universidade LaSalle, Canoas RS/Brasil; Bolsista PQ CNPq - 1 A - https://orcid.org/00000002-2546-6099 ; zilabster@gmail.com / zila.bernd@unilasale.edu.br
} 
argentina e quebequense. Trabalho pioneiro e de grande fôlego revelado pelo alentado número de escritores estudados entre os quais Antonio Torres, Gérard Bouchard e Juan Jose Saer.

Seu interesse pela temática estava apenas começando. Em 2018, publica com Rachel Bouvet, um conjunto de textos sobre a geopoética dos confins, desvendando o imaginário das literaturas nômades e inuits em emergência durante o século XX. Em 2019, suas pesquisas sobre as vozes de mulheres ameríndias são reunidas na importante publicação intitulada Ecrire l'espace des Amériques : représentations littéraires et voix de femmes amérindiennes, publicado pela editora P.I.E. Peter Lang (Nova York), na Coleção Brazilian Studies, vol. 5.

$\mathrm{Na}$ presente publicação da editora Makunaima, Rita Olivieri-Godet desvela as vozes de mulheres ameríndias nas literaturas brasileira e quebequense, brindando os leitores brasileiros com reflexão aprofundada e sensível sobre a obra de duas escritoras indígenas do Brasil e duas do Quebec, portanto, sobre escritoras que se exprimem em língua portuguesa e em língua francesa no território das Américas.

Eliana Potiguara e Graça Graúna são o destaque em língua portuguesa, enquanto Naomi Fontaine e Natasha Kanapé Fontaine são as autoras escolhidas do Quebec, província francófona do Canadá.

Eliane Potiguara está entre as primeiras a assumir a tarefa de descolonização de sua etnia, dando voz, pela primeira vez, em toda a história da literatura brasileira, àqueles que, embora tenham sido protagonistas da História do Brasil, foram silenciados durante todos estes anos. Merece destaque a dimensão híbrida da escrita de Eliane Potiguara, sublinhando em seu livro Metade cara, metade máscara, de 2004, o ponto de vista da mulher indígena que assume-se como sujeito da enunciação. Rita Olivieri-Godet destaca o importante papel da autora na denúncia da violência colonial e pós-colonial, apontando a metamorfose de identidade, "correlacionada à potencialização da voz".

É interessante ressaltar a importância, na obra poética de Eliane Potiguara, da memória ancestral: será somente ao reivindicar o legado da memória intergeracional que a identidade ameríndia vai sendo reconquistada:

Eu não tenho minha aldeia / Minha aldeia é minha casa espiritual / Deixada pelos meus pais e avós / A maior herança indígena.

Graça Graúna que é, além de poeta e ensaísta, professora universitária, desenvolve estratégias de sobrevivência para a cultura indígena através de várias coletâneas, entre as quais se destaca Tear da palavra, de 2007. Rita Olivieri-Godet sublinha também na obra de Graúna a intenção de reapropriar-se de suas referências culturais ameríndias, grande ausente do panorama cultural brasileiro. A poeta busca reinventar o lugar da poesia através do diálogo com os resquícios da memória ancestral, buscando representificar essa falta ao identificar-se com os demais excluídos, como os afro-descendentes, inaugurando, desta forma, um diálogo tanto no plano político quanto no literário. Expropriada do território geo-cultural de seus ancestrais, Graúna produz o que Rita Olivieri-Godet chama de "discurso transcultural", caracterizado pelo reconhecimento dos elementos da perda, os quais são compensados pela reinvenção de elementos culturais novos.

Ao fazer a leitura da obra Kuessipan (2011), de Naomi Fontaine, da literatura do Quebec, Rita Godet destaca o destino trágico do povo innu ${ }^{2}$, ressaltando os vínculos históricos dos povos autóctones com seu território. Na obra, a poeta questiona a segregação e recusa o confinamento nas reservas, que são espaços designados pelo governo, mantendo, assim, os povos indígenas

\footnotetext{
${ }^{2}$ As denominações "Innu" e "innuit" não são intercambiáveis; enquanto innu se refere aos indígenas que habitam a área, que denominam de Nitassinam (Our Land), e que corresponde à região onde hoje se situa a província do Quebec, os innuit são originários do Ártico, tendo sido por muito tempo chamados pelos brancos de "esquimós".
} 
segregados do resto dos habitantes do Canadá. Pertencendo a uma nova geração de poetas, Naomi Fontaine manifesta um sentimento ambivalente em relação à sua comunidade de origem, que é ao mesmo tempo de pertencimento e de desejo de abandono.

Em Kuessipan (que significa "para ti") Naomi Fontaine faz uma leitura intimista da reserva de Uashat que o sociólogo, historiador e romancista quebequense Gérard Bouchard descreveu em seu romance de mesmo nome de modo mais dicotômico, opondo a vida na reserva à vida nas cidades. Na leitura de Rita Olivieri-Godet, a narrativa de Naomi Fontaine faz um elogio do nomadismo e uma crítica do confinamento imposto pelo governo aos innus. "Nômade: gosto de conceber esse modo de viver como natural" (Fontaine, 2011, p. 22), explicita a autora, rendendo homenagem à característica de nomadismo dos povos autóctones e reivindicando essa característica como herança ancestral. Na visão da autora, da transmissão da herança depende o devir dessa comunidade: "Da transmissão da experiência do território tradicional dependia a sobrevivência material e cultural dos innus" (Olivieri-Godet, p. 95).

Natasha Kanapé Fontaine, também da linhagem de autoras ameríndias do Quebec, é a quarta e última autora estudada na obra que ora resenhamos. Natasha é militante dos direitos autóctones e ambientais e também poeta, atriz e pintora. É autora de N'entre pas dans mon âme avec tes chaussures (2012, prêmio de poesia da Sociedade dos Escritores Francófonos da América); do Manifeste Assi (2014); de Bleuets et abricots (2016) et Nanimissuat Île-Tonnerre (2018), sendo uma das escritoras mais produtivas da nova geração de autoras ameríndias.

Como as demais autoras, anteriormente estudadas por Rita Olivieri-Godet, Natasha realiza em suas obras o trabalho de recuperação memorial e de reapropriação do território geocultural de seus ancestrais, acrescentando o dever de memória de preservar e de transmitir essa herança, garantindo assim sua sobrevivência nos corações das futuras gerações.

As quatro escritoras vivem entre dois mundos. Rita Olivieri-Godet destaca em todas elas a prática de uma escrita da sobrevivência e uma determinação de incluir a presença autóctone no âmbito da literatura contemporânea. Se em trabalhos anteriores Rita Olivieri-Godet estudou a representação da presença autóctone em obras de autores contemporâneos, aqui ela traz aos leitores as vozes de mulheres ameríndias, analisando suas obras na perspectiva das relações literárias interamericanas, que é aliás nome do GT da ANPOLL ao qual nós duas pertencemos e no âmbito do qual desenvolvemos um comparatismo literário inter e transamericano.

\section{REFERÊNCIAS:}

GODET, Rita Olivieri. A alteridade ameríndia na ficção contemporânea das Américas (Brasil, Argentina, Quebec). Belo Horizonte: Fino Traço, 2013.

SANTOS, Eloína P. dos. A autoinclusão da literatura indígena contemporânea no cânone brasileiro: uma herança cultural a ser reconhecida. Revista literatura em debate, v. 12, p. 107121, 2018. 
Zilá Bernd é professora titular aposentada do Instituto de Letras da UFRGS e professora do Programa de Pós-Graduação em Memória Social e Bens Culturais da Universidade LaSalle/Canoas/RS. É pesquisadora $1 \mathrm{~A}$ do CNPq ; foi presidente da ABECAN (Associação Brasileira de Estudos Canadenses) e do ICC-CIEC (International Council for Canadian Studies). Recebeu a Ordem Nacional do Quebec e das Palmes académiques, ambas nos graus de chevalière et officière. Fundou a revista Interfaces Brasil Canadá, em 2001, permanecendo como membro do conselho editorial até os dias atuais. Entre suas publicações recentes, estão: A persistência da memória. Porto Alegre: Besouro Box, 2018; La persistance de la mémoire: les romans de l'antériorité et leurs modes de transmission intergénérationnelle. Paris: Société des écrivains, 2018 e BERND, Z.; IMBERT, P.; OLIVIERI-GODET, R. (dir) Espaces et littératures des Amériques; mutation, complémentarité, partage. Québec : Presses de 1’Université Laval, 2018.

Submetido em 03/05/2020

Aprovado em 13/06/2020 